
JURNAL
SABHANGA
Vol. 1 No. 2 Juli 2019 : 127-136
e-journal.stikessatriabhakti.ac.id

\title{
PENGARUH PENDIDIKAN KESEHATAN TENTANG AMPUTATUM TERHADAP \\ TINGKAT KECEMASAN PASIEN PRA OPERASI AMPUTATUM LUKA GANGREN \\ DI RSUD NGANJUK
}

\author{
Alifah Qur-aniyah ${ }^{1}$, Lexy Oktora Wilda ${ }^{2}$, Oktaffrastya Widhamurti Septafani ${ }^{3}$ \\ ${ }^{1}$ Mahasiswa STIKes Satria Bhakti Nganjuk, ${ }^{2,3}$ Dosen STIKes Satria Bhakti Nganjuk \\ Email:alifah.q@yahoo.com
}

\begin{abstract}
Introduction :The only way of gangrene wounds in diabetes is amputatum. Various surgical procedures make patients fear. Health education helps patients to improve and control emotions.This study aims to determine the effect of health education about amputatum on the level of anxiety preoperating patientsamputatum gangrene wounds in RSUD Nganjuk. Methods:The design of this study was Pre Experiment with One Group Pre-Post Design Test. The population of this study was 14 patients of pre op amputatum gangreneconducted on 14-17 December 2018 in RSUD Nganjuk and the sample in this study was 14 patientswith total sampling technique. The independent variables in this study washealth education about amputatumand the dependent variable was the level of anxiety.Data collection using SAP and Z-SASquestionnaire. Statistical test using Wilcoxon Signed Range Test with $\alpha=0.05$ in SPSS 20. Results: The results of the study of 14patients, the level of anxiety of patients with preoperative amputatum gangrenous injuries before being given health education most of the respondents were 9 respondents $(64.3 \%)$ included in the category of moderate anxiety and after being given health education in the majority of respondents as many as 9 respondents $(64.3 \%)$ included in the category of mild anxiety.Wilcoxon test results obtained $\rho$ value $=0.014$ with $\alpha=0.05$ so that $\mathrm{H}_{\mathrm{a}}$ was received, there was an effect of health education about amputatum on the level of anxiety preoperating patientsamputatum gangrene wounds in RSUD Nganjuk. Conclusion:one way to deal with preoperative amputatum anxiety was by communication.
\end{abstract}

Keywords : Health Education, Amputatum, The Level of Amputatum, Pre Operating, Gangrene Wounds

\section{PENDAHULUAN}

Luka gangren pada penyakit diabetes dengan jaringan yang sudah mati dan tidak bisa diperbaiki lagi, jalan satu-satunya adalah amputatum. Amputatum merupakan suatu tindakan pembedahan dengan membuang sebagian kecil atau besar bagian tubuh untuk meningkatkan kesehatan dan kualitas hidup pasien dan menghentikan kemajuan penyakit atau penyebaran penyakit (Demet, 2013). Berbagai prosedur pembedahan membuat pasien yang akan menjalani operasi amputatum mengalami banyak gejala yang ditimbulkan seperti susah tidur, gelisah, berkeringat dingin, jantung berdebardebar, dan rasa tidak nyaman pada perut seperti diare. Menurut data hasil studi pendahuluan yang dilakukan pada tanggal 22-27 Januari 2018 terhadap 13 pasien pra operasi amputatumluka gangrendi RSUD Nganjuk menunjukkan bahwa 9 pasien menolak karena ketidaksiapan dengan kondisi post operasi. Terlebih lagi banyak 
mengalami kegelisahan saat akan dilakukan operasi, seperti susah tidur, mengatakan perasaan berdebar-debar, dan sering buang air kecildan ketakutan yang membayangi mereka setelah operasi amputatum, seperti takut tidak bisa beraktifitas seperti sedia kala, ketidaknyamanan, nyeri post operasi, dan juga malu dengan kondisi tubuh yang tidak lengkap karena efek operasi amputatum. Hal tersebut dikarenakan ketidaktahuan mereka tentang operasi amputatum yang akan mereka jalani.

Menurut Crenshaw (2012) di Amerika Serikat terjadi 43.000 kasus pertahun dari jumlah penduduk 280.562.489 jiwa atau sekitar 0,02\% sedangkan menurut Raichle et al. (2012) disebutkan bahwa terjadi kasus amputasi sekitar 158.000 per tahun dari jumlah penduduk 307.212.123 atau sekitar 0,05\% dan terjadi kenaikan baik secara jumlah maupun secara persentase dari jumlah penduduk. Amputasi yang paling sering dilakukan adalah amputasi pada ekstremitas bawah mencapai $85 \%$ sampai 90\% dari seluruh amputasi. Menurut Vitriana (2012) angka kejadian pasti kasus amputasi di Indonesia tidak dapat diketahui. Berdasarkan data surveilens terpadu penyakit (STP) tahun 2015, kasus Diabetes Melitus di Provinsi Jawa Timur mencapai 108 pasien yang dirawat dan 934 pasien dirawat di puskesmas selama Januari hingga Juni 2009, (Supriadi, et al, 2015) Studiepidemiologi memperkirakan $2,5 \%$ pasien diabetes menjadi diabetic foot (DF) ulcers, dan setiap tahunnya 15\% menjadi diabetic foot ulcers seumur hidup. Diabetic foot adalah penyebab dari amputasi ekstremitas bawah lebih dari $85 \%$ kasus. Masalah ekstremitas bawah lebih sering mengalami komplikasi termasuk penurunan sensasi, yang memperberat terjadinya amputasi ekstremitas bawah pada seseorang dengan Diabetes Melitus (Cristina, 2013). Sementara di RSUD Nganjuk pada tahun 2017 dari 130 kasus luka gangrene pada pasien diabetes melitus, yang bersedia dilakukan amputatummencapai 63 kasus dan 67 kasus menolak dilakukan amputatum sehingga hanya dilakukan debridement.

Kecemasan yang biasanya terungkap sebelum dilakukan pembedahan menurut Efendy (2005) dalam Larasati (2009) antara lain, kecemasan munculnya rasa nyeri, kecemasan terjadi perubahan fisik (menjadi buruk rupa dan tidak berfungsi secara normal), kecemasan keganasan (bila diagnosa yang ditegakkan belum pasti), kecemasan memasuki Ruang Operasi, kecemasan menghadapi peralatan bedah dan petugas, kecemasan mati saat dilakukan anestesi, serta kecemasan 
apabila operasi akan mengalami kegagalan. Tidak heran jika sering kali pasien dan keluarganya menunjukkan sikap yang berlebihan dengan kecemasan yang mereka alami. Beberapa orang kadang tidak mampu mengontrol kecemasan yang dihadapi, sehingga terjadi disharmoni dalam tubuh. Dampak kecemasan sebelum operasi apabila tidak segera diatasi akan meningkatkan tekanan darah dan pernafasan yang dapat menyebabkan pendarahan baik pada saat pembedahan ataupun pasca operasi.

Menurut Potter dan Perry (2006) dalam Nainggolan (2010) perawat sebagai pelaksana dalam memberikan asuhan keperawatan pada pasien yang akan menghadapi tindakan operasi mempunyai tanggung jawab besar dalam pemenuhan kebutuhan dasar manusia, yaitu salah satunya penanganan rasa cemas. Saat ini telah banyak dikembangkan terapi keperawatan untuk menangani kecemasan, salah satunya seperti pada penelitian Heppy (2013)terdapat terapi relaksasi otot progresif sebagai peregangan otot tetapi karena waktu pelaksanaannya yang terlalu lama sehingga tidak memungkinkan dilaksanakan di dalam bangsal perawatan. Selain itu, salah satu cara untuk menangangi kecemasan pre operasi amputatum yaitu dengan komunikasi. Misalnya penjelasan tentang prosedur tindakan. Proses informed consent juga merupakan manisfetasi dari terpeliharanya hubungan saling menghormati dan komunikasi antara petugas kesehatan dengan pasien, yang bersama-sama menentukan pilihan tindakan yang terbaik bagi pasien demi mencapai tujuan pelayanan kedokteran yang disepakati (Medical Counsil, 2006). Disamping itu, manfaat pendidikan kesehatan menurut Musliha dan Fatmawati (2010) adalahmembantu pasien dalam memperbaiki dan mengendalikan emosi sehingga membantu mempercepat penyembuhan dari upaya medis.

\section{METODE PENELITIAN}

Desain penelitian pada penelitian ini menggunakan Pra eksperimental dengan pendekatan One group pre-post test design. Penelitian ini dilaksanakan mulai tanggal 14-17 Desember 2018 diRSUD Nganjuk. Besar populasi pasien pre op amputatum luka gangren yang dirawat di RSUD Nganjukberjumlah 14 orang. Sampel pada penelitian ini adalah pasien pre op amputatum luka gangren yang dirawat di RSUD Nganjukberjumlah 14orang. Penelitian ini menggunakan teknik sampling total sampling. Variabel independen pada skripsi ini ialah pendidikan kesehatan tentang amputatumdan variabel dependen pada skripsi ini ialah tingkat kecemasan. 
Instrumen atau alat ukur pada penelitian dan variabel dependen menggunakan skala ini variabel independen menggunakan SAP Z-SAS.

\section{HASIL}

1. Tingkat kecemasan pasien pra operasi amputatum luka gangren sebelum diberikan pendidikan kesehatan.

Tabel 1 Distribusi frekuensi tingkat kecemasan pra operasi sebelum diberikan pendidikan kesehatan tentang amputatum di RSUD Nganjuk pada tanggal14-17 Desember 2018.

\begin{tabular}{ccc}
\hline Tingkat Kecemasan & Frekuensi $(f)$ & Persentase (\%) \\
\hline Kecemasan ringan & 3 & 21.4 \\
\hline Kecemasan sedang & 9 & 64.3 \\
\hline Kecemasan berat & 2 & 14.3 \\
\hline Panik & 0 & 0 \\
\hline Total & 14 & 100.0 \\
\hline
\end{tabular}

Berdasarkan tabel 1 dapat diketahui dapat diketahui dari 14 responden sebelum diberikan pendidikan kesehatantentang amputatum sebagian besar masuk dalam kategori kecemasan sedang sebanyak 9responden (64.3\%).

2. Tingkat kecemasan pasien pra operasi amputatum luka gangren setelah diberikan pendidikan kesehatan.

Tabel 2 Distribusi frekuensi tingkat kecemasan pra operasi setelah diberikan pendidikan kesehatan tentang amputatum di RSUD Nganjuk pada tanggal14-17 Desember 2018.

\begin{tabular}{ccc}
\hline Tingkat Kecemasan & Frekuensi $(f)$ & Persentase $(\%)$ \\
\hline Kecemasan ringan & 9 & 64.3 \\
\hline Kecemasan sedang & 3 & 21.4 \\
\hline Kecemasan berat & 2 & 14.3 \\
\hline Panik & 0 & 0 \\
\hline Total & 14 & 100.0
\end{tabular}

Berdasarkan tabel 2 dapat diketahui dari dari 14 responden setelah diberikan pendidikan kesehatan tentang amputatum sebagian besarmasuk dalam kecemasan ringan sebanyak 9responden (64.3\%).

3. Pengaruhpendidikan kesehatan tentang amputatum terhadap tingkat kecemasan pasien pra operasi amputatum luka gangren di ruang RSUD Nganjuk.

Tabel 3 Tabulasipengaruh pendidikan kesehatan tentang amputatum terhadap tingkat kecemasan pasien pra operasi amputatum luka gangren di RSUD Nganjuk pada tanggal14-17 Desember 2018.

\begin{tabular}{ccccc}
\hline \multirow{2}{*}{ Tingkat Kecemasan Pra Operasi } & \multicolumn{2}{c}{ Sebelum } & \multicolumn{2}{c}{ Sesudah } \\
\cline { 2 - 5 } & $f$ & $(\%)$ & $f$ & $(\%)$ \\
\hline Kecemasan ringan & 3 & 21.4 & 9 & 64.3 \\
\hline Kecemasan sedang & 9 & 64.3 & 3 & 21.4 \\
\hline Kecemasan berat & 2 & 14.3 & 2 & 14.3 \\
\hline Panik & 0 & 0 & 0 & 0 \\
\hline Total & 14 & 100.0 & 14 & 100.0 \\
\hline & $\boldsymbol{\rho}$ (value) $\mathbf{0 0 . 0 2} \leq \boldsymbol{\alpha}=\mathbf{0 . 0 5}$ & & \\
\hline
\end{tabular}


Berdasarkan tabel 3 diketahui hasil uji statistik Wilcoxon Signed Ranks Test dengan $\boldsymbol{\alpha}=0.05$ dan didapatkan $\rho$ (value) $=0.014 \leq \alpha=0,05$ maka $\mathrm{H}_{\mathrm{a}}$ diterima dan ada pengaruh pendidikan kesehatan tentang amputatum terhadap tingkat kecemasan pasien pra operasi amputatum luka gangren di RSUD Nganjuk.

\section{PEMBAHASAN}

1. Tingkat kecemasan pasien pra operasi amputatum luka gangren sebelum diberikan pendidikan kesehatan.

Berdasarkan hasil penelitian memperlihatkan bahwa tingkat kecemasan pra operasi sebelum diberikan pendidikan kesehatan tentang amputatum dari 14 responden sebagian besar masuk dalam kategori kecemasan sedang sebanyak 9responden (64.3\%).Dari 9 responden yang memiliki kecemasan sedang hampir setengahnya yaitu 3 responden $(33.3 \%)$ memiliki rentang usia 31-40 tahun dan hampir setengahnya yaitu 3 responden memiliki usia $>50$ tahun, hampir setengahnya yaitu 4 responden (44.4\%) memiliki tingkat pendidikan SD dan hampir setengahnya yaitu 4 responden (44.4\%) memiliki tingkat pendidikan SMP, dan hampir seluruhnya yaitu 8 responden (100\%) belum pernah memiliki pengalaman operasi sebelumnya. Hasil uji statistik didapatkan $p$ value usia=0.042, $\quad p \quad$ value pendidikan $=0.002, \quad$ dan $p$ value pengalaman operasi $=0.008$. Karena $p$ valueusia, pendidikan, danpengalaman operasi sebelumnya $\leq \alpha=0.05$ maka tingkat kecemasan pra operasi sebelum diberikan pendidikan kesehatan tentang amputatum dipengaruhi oleh usia, pendidikan, dan pengalaman operasi sebelumnya secara signifikan.

Dari hasil uraian diatas terdapat ketidakselarasan antara fakta dan teori. Fakta dilapangan menunjukkan bahwa sebagian besar responden belum pernah memiliki pengalam operasi sebelumnya dan setengahnya responden masuk dalam kecemasan sedang. Hal ini dimungkinkan karena sebelum diberikan pendidikan kesehatan tentang amputatum, responden belum yang belum memiliki pengalaman operasi juga memiliki pengetahuan terbatas tentang amputatum sehingga diperlukan pendidikan kesehatan kepada pasien dengan indikasi amputatum supaya pasien memiliki pengetahuan yang cukup tentang amputatum dan bisa melancarkan 
tindakan medis yang harus dilakukan kepada pasien guna kesehatan pasien.

2. Tingkat kecemasan pasien pra operasi amputatum luka gangren setelah diberikan pendidikan kesehatan.

Berdasarkan hasil penelitian memperlihatkan bahwa tingkat kecemasan pra operasi setelah diberikan pendidikan kesehatan tentang amputatum dari 14 responden sebagian besar masuk dalam kecemasan ringan sebanyak 9 responden (64.3\%). Dari 9 responden yang memiliki kecemasan ringan hampir setengahnya yaitu 4 responden (44.4\%) memiliki tingkat pendidikan SMP. Hasil uji statistic didapatkan $\quad p \quad$ valuetingkat pendidikan $=0.001$. Karena $p$ value belum pernah memiliki pengalaman operasi sebelumnya $\leq \alpha=0.05$ maka tingkat kecemasan pra operasi sebelum diberikan pendidikan kesehatan tentang amputatum dipengaruhi oleh tingkat pendidikan secara signifikan.

Dari hasil uraian diatas terdapat keselarasan antara fakta dan teori. Fakta dilapangan menunjukkan bahwa hampir setengah responden memiliki tingkat pendidikan SMP dan hasil setelah diberikan pendidikan kesehatan tentang amputatumsebagian besar masuk dalam kecemasan ringan. Hal tersebutdapat disimpulkan bahwa tingkat pendidikan sebagai indikator yang dapat diperoleh dalam mencapai keberhasilan suatu proses pendidikan kesehatan. Hal ini dapat diartikan bahwa dengan memberikan pendidikan kesehatan tentang amputatum yang diberikan selama 30 menit sudah dapatmemberikan informasi kepada responden untuk mengatasi kecemasan pra operasi.

3. Menganalisis pengaruh pendidikan kesehatan tentang amputatum terhadap tingkat kecemasan pasien pra operasi amputatum luka gangren di RSUD Nganjuk Tanggal14-17 Desember 2018.

Berdasarkan hasil uji statistik Wilcoxon Signed Ranks Test dengan $\alpha$ $=0.05$ dan didapatkan hasil $\rho$ (value) $=0.014$ sehingga $\rho$ (value) $\leq \alpha$, hal ini menunjukkan Ha diterima dan ada pengaruh pendidikan kesehatan tentang amputatum terhadap tingkat kecemasan pasien pra operasi amputatum luka gangren di RSUD Nganjuk.

Dari uraian diatas berdasarkan fakta dan teori maka melakukan pendidikan kesehatan tentang 
amputatumdapat mempengaruhi tingkat kecemasan pasien pra operasi amputatum luka gangren di RSUD Nganjuk. Hal tersebut dikarenakan responden sudah mendapatkan informasi kesehatan tentang amputatum, penyebabamputatum, faktor yang mempengaruhi amputatum, tingkatanamputatum, dan prinsip dasar penyembuhan luka amputatum.

\section{KESIMPULAN}

Tingkat kecemasan pasien pra operasi amputatum luka gangren sebelum diberikan pendidikan kesehatan di RSUD Nganjuk sebagian besarresponden sebanyak 9responden (64.3\%)masuk dalam kategori kecemasan sedang dan setelah diberikan pendidikan kesehatan di RSUD Nganjuk sebagian besarresponden sebanyak 9responden (64.3\%) masuk dalam kecemasan ringan.Ada pengaruh pendidikan kesehatan tentang amputatum terhadap tingkat kecemasan pasien pra operasi amputatum luka gangren di RSUD Nganjuk. Hal ini berdasarkan hasil uji statistik Wilcoxon Signed Ranks Test dengan $\boldsymbol{\alpha}=0.05$ dan didapatkan hasil $\rho$ $($ value $)=0.014$ sehingga $\rho($ value $) \leq \alpha$ dan Ha diterima.

\section{SARAN}

\begin{tabular}{ll}
\multicolumn{2}{c}{ Diharapkan dapat membantu } \\
responden dalam memanajemen
\end{tabular} kecemasan sehingga dapat meningkatkan kenyamanan selama menunggu proses tindakan operasiamputatumdan memberikan bukti klinis tentang manfaat pendidikan kesehatan terhadap penurunan kecemasan pada pasien pra operasi amputatum luka gangren sehingga dapat dijadikan bahan rujukan dalam memberikan asuhan keperawatan secara komprehensif. Bagi dunia pendidikan dapat menambah koleksi dan jumlah kajian ilmiah khususnya tentang manajemen kecemasan pada pasien pra operasi amputatum luka gangren, dapat menjadi bahan kajian penelitian selanjutnya dalam mengembangkan asukan keperawatan yang lebih berkualitas.

\section{DAFTAR PUSTAKA}

Arikunto, S. (2006). Prosedur Penelitian Suatu Pendekatan Praktik. Jakarta: Rineka Cipta.

Asmadi. (2010). Teknik Prosedural Keperawatan Konsep Dan Aplikasi Kebutuhan Dasar Klien. Jakarta : Salemba Mediska.

Atkinson, L.J \& Fortunato, N.H.(1992). Berry \& Kohn's Operating Room Technique ( $8^{\text {th }}$ ed). Missouri: Mosby.

Attree, M. \& Merchant, J. 2000. Belajar Merawat di Bangsal Bedah. Jakarta: EGC.

Brunner dan Suddarth, 2001. Buku Ajar Keperawatan Medikal Bedah. Edisi 8, Volume 1. Jakarta: EGC

Burger, H. (2012). Functioning of persons following lower limb amputation 
patients' perspective, Medicina Fluminensis, 48 (4), 471-479.

Cangara, Hafied. (2002). Pengantar Ilmu Komunikasi. Jakarta : Raja Grafindo Persada

Cavanagh, P.R., Lipsky, B.A., Bradbury, A.W., \& Botek, G. (2006). Treatment for diabetic foot ulcers. Lancet, 366, 1725-35.

Cavanaugh, M. A., Boswell, W. R., Roehlin, M. V., \& Boudreau, J. W. (2000). An empirical examination of self-reported work stress among U.S. managers. Journal of Applied Psychology, 85, 65-74.

Chini, G., Cristina, O., Boemer, M., Roseira. (2007). Amputation in the perception of those who experience it a study under the phenomenological view, 15 (2), 330-6

Dalami, Ernawati, Dkk. (2009). Asuhan Keperawatan Jiwa Masalah Psikososial. Jakarta : Trans Info Inda.

Dalami. (2014). Asuhan Keperawatan Jiwa Dengan Masalah Psikososial. Jakarta: Trans Indo Medika.

Davidson, J.A. (2002). Survey of the satisfaction of upper limb amputees with their prostheses. Their Lifestyles and Their Abilities, $J$ Hand Ther, 15 (1), 62-70.

Davidson, J.H., Jones, L.E., Cornet, J. \& Cittarelli, T. (2002). Management of the multiple limb amputee. Disability and Rehabilitation, 24, 688-699.

Demet, K., Martinet, N., Guillemin, F., Paysant, J., \& Andre, J. M. (2003). Health related quality of life and related factors in 539 persons with amputation of upper and lower limb. Disabil Rehabil, 25 (9), 480-6.
Doenges, M,E., Townsend M,C., \& Moorhouse. (2007). Rencana asuhan keperawatan psikiatri, EGC, Jakarta.

Effendy, Onong Uchjana. (2005). Ilmu Komunikasi: Teori dan Praktek. Bandung : PT. Remaja Rosdakarya

Ellis dkk. (1999). Komunikasi Interpersonal dalam Keperawatan (Edisi Terjemahan). Jakarta: EGC.

Hawari, Dadang. (2006). Manajemen Stress Cemas Dan Depresi, Edisi 2, jakarta : FKUI.

Henderson \& Chien (2004). Information Needs Of Hongkong Chinese Pasients Undergoingsurger. Dibuka pada website:http://www.blackwellsynergy. com/doi/abs/10.1111/j.13652702.2004.01004.

Hidayat, A.A.A. (2014). Metode Penelitian Keperawatan dan Teknis Analisis Data. Jakarta: Salemba Medika.

Kozier et al, 2004. Fundamental Of Nursing ; Concepts, Process And Practice $7^{\text {nd }} E d$. New Jersey : Pearson Prentice Hall.

Kusmawan, Eka. 2011. Jangan Segera Katakan 'Ya', Untuk Operasi. Edisi Pertama. Yogyakarta: Pohon Cahaya.

Liu, F., Williams, R. M., Liu, Hsueh-E., \& Chien, N-H. (2010). The lived experience of persons with lower extremity amputation. Journal of Clinical Nursing, 19, 2152-2161.

Livingstone, W., Mortel, T.F. Van, D., \& Taylor, B. (2011). A path of perpetual resilience. Exploring the experience of a diabetes related amputation through grounded theory. Content Management Pty Ltd Contemporary Nurse, 39 (1), 20-30 
Lukman., Ningsih, N. (2009). Asuhan keperawatan pada klien dengan gangguan sistem muskuloskeletal, Salemba Medika, Jakarta.

Lumongga, Pieter. (2010). Pengantar Psikologi Dalam keperawatan, Jakarta : Kencana.

Marlindawani dkk. (2011). Asuhan Keperawatan Pada Klien dengan Masalah Psikologi dan Gangguan Jiwa. Medan. USU Press

Medical Counsil. 2006. Manual Persetujuan Tindakan Kedokteran.

Morbidity and Mortality Weekly Report [MMWR]. (2003). Lower extremity amputation episodes among persons with diabetes New Mexico, morbidity and mortality weekly report, 66 .

Mozumdar, A., \& Roys, S. K. (2010). Depression in adult males with lower extremity amputa-tion and its biosocial correlates, 2 (8), 878-889.

Musliha \& Fatmawati, S. (2010). Komunikasi Keperawatan Plus Materi Komunikasi Terapeutik. Yogjakarta: Nuha Medika

Nasir, A., Muhith, A., Sajidin, M \& Mubarak, W.I. (2011). Komunikasi Dalam Keperawatan Teori dan Aplikasi. Jakarta: Salemba Medika.

Notoatmojo, S. (2003). Pengantar Pendidikan Kesehatan dan Ilmu Perilaku. Yogyakarta: Andi Offset.

Notoatmojo, S.. (2012). Promosi Kesehatan dan Ilmu Perilaku. Jakarta : Rineka Cipta

Nurhasanah, N. (2009). Ilmu Komunikasi Dalam Konteks Keperawatan. Jakarta: TIM.

Nursalam. (2014). Konsep Dan Penerapan Metodologi Penelitian Ilmu
Keperawatan. Edisi 2. Jakarta: Salemba Medika.

Oermarjoedi, Kasandra. (2004).

Pendekatan Kognitif Behaviour dalam psikotherapy, Jakarta: Creative Media

Phelps, L,F., Williams, R,M., Raichle, K.A., Turner, A,P., \& Ehde, D.M. (2008). The importance of cognitive processing to adjustment in the 1st year following amputation. Rehabilitation psychology, 53, 28-38.

Potter, P.A \& Perry, A.G. (2005). Buku Ajar Fundamental Keperawatan: Konsep, Proses, dan Praktik edisi 4 volume 1. Jakarta : EGC.

Potter, P. A., \& Perry, A, G. (2009). Fundamentals of nursing; Fundamental keperawatan (edisi 7). Jakarta, Salemba Medika.

Purwanto, H. (1994). Komunikasi untuk perawat. Jakarta: EGC.

Rybarczyk, B., Edwars, R., \& Behel, J. (2004). Diversity in adjusment to a leg amputation, case illustrations of common themes disabil rehabil.

Rybarczyk, B.D., Nyenhuis, D.L., Nicholas, J.J., Cash, B., \& Kaiser, J. (1995). Body image, perceived social stigma and the prediction of psychosocial adjustment to leg amputation. Rehabilitation Psychology, 40, 95-110.

Roper, Nancy, 2002. Prinsip-Prinsip Keperawatan, Edisi Pertama. Jakarta: Yayasan Essentia Medica.

Roy, C. (2011). The Roy adaptation model. Philadelphia: Lippincott Williams and Wilkins.

Senra, H., Oliveira, R. A., Leal, I., \& Veira, C. (2011). Beyond the body image : A qualitative on how adults experience lower limb amputation, 
Clinical Rehabilitation, 26 (2), 180191.

Siswanto, (2007). Kesehatan Mental: konsep, cakupan dan perkembangan. Jakarta : ANDY Yogyakarta.

Sjamsuhidajat, R. (2005). Ilmu Bedah, Edisi Revisi. Jakarta: EGC.

Smeltzer, S. C \& Bare, B. G., (1996). Buku Ajar Keperawatan Medikal Bedah. Jakarta: EGC.

Smeltzer, S. C., Bare, B.G, Hinkle, J.L., Cheever, K.H. (2008). eds, Brunner \& suddath's textbook of medical surgical nursing, 11 th ed. Philadelphia, PA: Lippincott Williams and Wilkins.

Smeltzer, S. C. (2010). Brunner and suddarth's textbook of MedicalSurgical nursing (12 th ed). Philadelphia, Lippincott Williams \& Wilkins.

Society Vascular Nursing [SVN]. (2008). Lower extremity amputations, brought to you by the education committee of the society for vascular nursing.

Stuart \& Sundeen, s1998. Prinsip dan Praktek Keperawatan Jiwa (Edisi Terjemahan). Jakarta: EGC.

Stuart, G.W. (2007). Buku saku keperawatan jiwa, EGC, Jakarta.
Sugiyono. (2010). Statistika Untuk Penelitian. Bandung: Alfa Beta.

Suliswati, dkk. (2009). Konsep Dasar Keperawatan Kesehatan Jiwa, Jakarta: EGC.

Supriyanto, S \& Ernawaty. (2010). Pemasaran Industri Jasa Kesehatan. Yogyakarta: 2010.

Suryani. (2006). Komunikasi Terapeutik Teori \& Praktik. Jakarta: EGC

Tamsuri, Anas, 2006. Komunikasi dalam Keperawatan. Cetakan pertama, EGC, Jakarta.

Taylor, C. (1997). Fundamental of nursing the art and science of nursing care (3th edition). Philadelpia: Lippincott Company.

Vitriana, dr. (2002). Rehabilitasi pasien amputasi bawah lutut dengan menggunakan immediate post operative prosthetic.

Wahid, A. (2013). Asuhan keperawatan dengan gangguan sistem muskuloskeletal, Trans Info Media, Jakarta.

Wiramiharja, Sutardjo, A. (2007). Pengantar Psikologi Abnormal, Bandung : Refika Aditama 